\title{
Calcific tendinitis of the gluteus maximus of a 53-year-old woman
}

\author{
Kun Huang MD PhD, Darra Murphy MB, Natasha Dehghan MD
}

Cite as: CMAJ 2017 December 18;189:E1561. doi: 10.1503/cmaj.171308

A healthy 53-year-old woman presented with sudden onset of severe pain in the left buttock. She had not experienced an injury and felt well otherwise. On examination, there was exquisite tenderness even on light palpation of the left buttock and lateral aspect of the upper thigh. Range of motion in the left hip and lumbar spine was normal, with no pain. The remainder of the examinations of the musculoskeletal and neurologic systems was normal. Blood work was remarkable only for a mildly elevated C-reactive protein level at 19 (normal <3) mg/L. Radiography and computed tomography of the lumbar spine and pelvis were normal, apart from calcifications at the insertion of the gluteus maximus tendon to the femoral metaphysis (Figure 1), corresponding to the area of maximal tenderness on examination. The location of the pain, in conjunction with soft tissue calcification seen on imaging, was diagnostic for calcific tendinitis of the gluteus maximus.

Acute onset of calcific tendinitis provokes an inflammatory response and can be extremely painful. The most common anatomic location is the supraspinatus tendon in the glenohumeral joint; hip involvement is much less common. ${ }^{1}$ Reported sites for calcium deposition around the hip are illustrated in Appendix 1 (available at www.cmaj.ca/lookup/suppl/doi:10.1503/cmaj. 171308/-/DC1). ${ }^{2}$ On imaging, a comet-tail appearance of calcification may be seen at the intratendinous location of the calcium deposit. ${ }^{3}$ Uncommonly, on imaging, calcific tendinitis may be associated with cortical erosion, which can be mistaken for infection or neoplasm. Biopsy should be avoided when the radiologic findings are diagnostic of calcific tendinitis, despite evidence of osseous involvement. ${ }^{2,3}$ The role of the radiologist cannot be overemphasized in these cases.

Treatments include physiotherapy, analgesia, cortisone injection and, in recalcitrant cases, barbotage (ultrasound-guided percutaneous needle aspiration and lavage). ${ }^{3,4}$ Our patient under- went an ultrasound-guided methylprednisolone and bupivacaine injection around the gluteus maximus tendon insertion, with good response.

\section{References}

1. Pope TL Jr, Keats TE. Case report 733. Calcific tendinitis of the origin of the medial and lateral heads of the rectus femoris muscle and the anterior iliac spin (AllS). Skeletal Radiol 1992;21:271-2.

2. Flemming DJ, Murphey MD, Shekitka KM, et al. Osseous involvement in calcific tendinitis: a retrospective review of 50 cases. AJR Am J Roentgenol 2003;181:965-72.

3. Mizutani H, Ohba S, Mizutani M, et al. Calcific tendinitis of the gluteus maximus tendon with cortical bone erosion: CT findings. J Comput Assist Tomogr 1994;18:310-2.

4. Jo H, Kim G, Baek S, et al. Calcific tendinopathy of the gluteus medius mimicking lumbar radicular pain successfully treated with barbotage: a case report. Ann Rehabil Med 2016;40:368-72.

\section{Competing interests: None declared.}

This article has been peer reviewed.

The authors have obtained patient consent.

Affiliations: Division of Rheumatology (Huang, Dehghan), University of British Columbia; Department of Radiology (Murphy), St Paul's Hospital, Vancouver, BC

Correspondence to: Kun Huang, khuang@cmmt.ubc.ca 